\title{
OA10.04. Effectiveness of integrated yoga therapy in treatment of chronic migraine: randomized controlled trial
}

\author{
P Sharma ${ }^{1 *}$, N Sharma $^{2}$ \\ From International Research Congress on Integrative Medicine and Health 2012 \\ Portland, Oregon, USA. 15-18 May 2012
}

\section{Purpose}

The present study was undertaken to evaluate whether an integrated yoga therapy program helps in reducing pain measures and depression in chronic migraine patients.

\section{Methods}

To test the effectiveness of an integrated yoga therapy program for chronic migraine treatment in a low cost, nonclinical setting, a prospective, randomized, controlled trial was conducted in Jaipur, India. Subjects aged 18 to 65 years with 15 or more headache days per month, at least half of which were migraine/ migrainous headaches, were randomized 1:1 to either yoga therapy or standard management. Seventy men and women were randomly assigned. The intervention group went through individualized yoga treatment for 12 -weeks with 4 consecutive therapeutic sessions a week. Each therapy session lasting for about $60 \mathrm{~min}$ utes focusing on strengthening, relaxation, releasing muscular tension and increasing self-efficacy. The control group consisted of standard care with the patient's physician. Outcome measures included selfperceived pain intensity, frequency, and duration; functional status; depression; prescription and nonprescription medication use. Outcomes were measured at the end of the 12-week intervention and at a 6-month follow-up.

\section{Results}

Thirty-one of 35 patients from the intervention group and all 35 patients from the control group completed the study. There were no statistically significant differences between the two groups before the intervention. Intention to treat analysis revealed that the intervention group experienced statistically significant changes in self-perceived pain frequency $(\mathrm{p}<.001)$, pain intensity $(\mathrm{p}=.001)$, pain duration $(\mathrm{p}<.001)$, functional status $(\mathrm{p}<.001)$, medication used $(\mathrm{p}<0.01)$ and depression $(\mathrm{p}<.001)$; these differences retained their significance at the 6-month follow-up.

\section{Conclusion}

Positive health related outcomes in chronic migraine can be obtained with a low cost, group, integrated yoga in a community based nonclinical setting.

\section{Author details}

'NMP Medical Research Institute, Jaipur, India. ${ }^{2}$ Brett Research (UK), London, United Kingdom.

Published: 12 June 2012

doi:10.1186/1472-6882-12-S1-040

Cite this article as: Sharma and Sharma: OA10.04. Effectiveness of integrated yoga therapy in treatment of chronic migraine: randomized controlled trial. BMC Complementary and Alternative

Medicine 2012 12(Suppl 1):O40.

${ }^{1}$ NMP Medical Research Institute, Jaipur, India

Full list of author information is available at the end of the article

(c) 2012 Sharma and Sharma; licensee BioMed Central Ltd. This is an Open Access article distributed under the terms of the Creative 